\title{
Futsal and the Social Culture: Integration of Practice of Futsal in the Programming of Physical Education and Sports in Tunisia
}

\author{
Nejah Kacem ${ }^{1}$, Chokri Naffeti², Ayman Guemri' ${ }^{3}$, Ali Elloumi' \\ ${ }^{1}$ State, Culture and Change of Society, Higher Institute of Sport and Education Physics Ksar Saïd, Mannouba, \\ Tunisia \\ ${ }^{2}$ Group for the Study of Development and Social Environment (GEDES), Faculty of Human and Social Science of \\ Tunis, Tunis, Tunisia \\ ${ }^{3}$ Educational Department of PAS, Higher Institute of Sport and Education Physics of Sfax, Sfax, Tunisia \\ Email: kacemnejah@gmail.com
}

Received 12 July 2016; accepted 16 August 2016; published 19 August 2016

Copyright (C) 2016 by authors and Scientific Research Publishing Inc.

This work is licensed under the Creative Commons Attribution International License (CC BY).

http://creativecommons.org/licenses/by/4.0/

\section{(c) (i) Open Access}

\section{Abstract}

Physical education and sport are an integral part of education. Its major components in the education system are clearly defined. Objectives express an identity of integral education of the child. However, certain principles in the development of physical and sports education objectives allow the definition of the capabilities in the school environment and the effectiveness of teaching. In our research we have noticed that the number of participants in the course of physical education and sports decreases in remarkable ways. Indeed both researches have explained this phenomenon to psychological such as adolescence and physiological as obesity factors. While this phenomenon can be explained following the analysis of the direct interaction teaching and content of education. The objective of this study is to know the impact of the integration of new sport which is our investigation such as Futsal on the motivation of participants and the resolution of this problem.

\section{Keywords}

Educational Content (Internal Didactic Transposition), Integration of New Sport, Motivation, Effectiveness of Teaching, Futsal

\section{Introduction}

Sports as students-activating factor provide a spirit of emulation and motivation and no constraint for learning

How to cite this paper: Kacem, N., Naffeti, C., Guemri, A., \& Elloumi, A. (2016). Futsal and the Social Culture: Integration of Practice of Futsal in the Programming of Physical Education and Sports in Tunisia. Advances in Physical Education, 6, 257267. http://dx.doi.org/10.4236/ape.2016.63027 
and demonstration of authority. It is thus, that the teacher will be able to attract the interest of students and make them love the course of physical education and sports to create patterns of activity. However, many studies have shown that it remains a discipline in the margins of the educational system for many reasons: the youth of the discipline, and representations that it conveys, the places of practice and the nature of the activity of student. Physical and sports education undergoes various representations. This discipline often has great difficulty out of the roles that has given it within the educational system. We have sought to know the great lines of representation of content of this discipline by students in the classes of the secondary school, girls and boys in the region of Sfax in Tunisia, trying to highlight the usefulness and interest granted by these students to this matter and their opinions with regard to the educational content offer. Physical education as it is about the nature of a human being, and more particularly of a child, to make it able to freely perform certain acts and to target certain purposes considered as desirable in a given civilisation, is a genuine and important area of general education. It constitutes the condition and the necessary accompaniment of any other mode of education, because it gives for object the acquisition of existence. More than the simple maintenance of body and spirit in a satisfactory balance, it seems to have to be considered as the ability of an individual, constantly adjust its reactions and behaviors to the conditions of the outside world, to get accustomed to the effort. It is therefore on the individual as a whole, and contributes to the formation of his personality by helping it to flourish physically intellectually and morally. Furthermore, physical and sports education must be the echo, in educational terms, of the growing importance of sport as a result of civilization. It is regarded as a discipline, cannot be limited to the only education of the body, and speaks to man in its totality. The development is indispensable for the concepts learned from this research.

\section{Theoretical Approach}

Physical education and sport in Tunisia: Physical and sports education in Tunisia is an essential core of image of cultural progress, regarded as one of the paramount concern of the Ministry of sport and youth, it constitutes one of the most important concerns of the Government. Indeed physical and sports education in Tunisia has known a remarkable maturation that manifests as a pedagogical approach recognized by "by objectives", which is a technique of formulation of the objectives of education and pedagogy that has highlighted the need to focus the attention of education and the student on the product of the educational action. Physical education in Tunisia, like other matters of general education, fixed in advance its aims by providing some guidelines to its educational system. Those purposes are contained in the official texts aimed at improving student mental and physical qualities. Parlebas: "physical education is a practice of intervention which affects motor lines of participants on the basis of educational standards implicit or explicit. The exercise of this normative influence usually causes a transformation of the motor lines. "However, the purposes cited by official instructions contain: knowledge to teach and its ability to adapt and overcome a problem by the essential development of as decisive driving availability of quick and easy adaptability to the requirements of the situations, and refinement of psychomotor structures and strengthening of the body schema. The discovery of gestures key motor with progressive searching for their greater efficiency; organic development and acquisition of motor skills varied relating to all drive components. The practice of these activities must be discerned clearly. Should therefore be by physical activities and sports seem to be the most suitable for any particular purpose. However it is possible to obtain different educational effects, according to the educational intention of the teacher.

The transposition is a central concept of the work in the teaching of school subjects (Figure 1). The authorship of the term is attributed to Mercier (2002), its distribution is mainly carried out by Chevallard (1985). This author defines the didactic transposition, in its strict sense, as "work which of one object to actually teach a learning object. This concept is indeed essential to understand the transformations that undergoes social and scientific knowledge to be taught. School learning traditionally present as self-evident, undoubtedly necessary, was taught to a homogeneous school public adapted to the requirements of the school until the 1960s. The massification of the English, the consequences it entails and the heterogeneity of classes questioned the proposed lessons, forced the education system partners to question the relevance and quality of the delivered content and teaching, teaching objects are now at the centre of the school questions. It is accepted that the school learning can be copy of knowledge formalized at a high level of expert practice. The school must form it means preparing students to become citizens of their time. Y. Chevallard shows in this connection, the importance of the noosphere in these choices. The didactic transposition correlates multiple scientific fields: Linguistics, 
The didactic transposition:

External didactic transposition

Internal didactic transposition

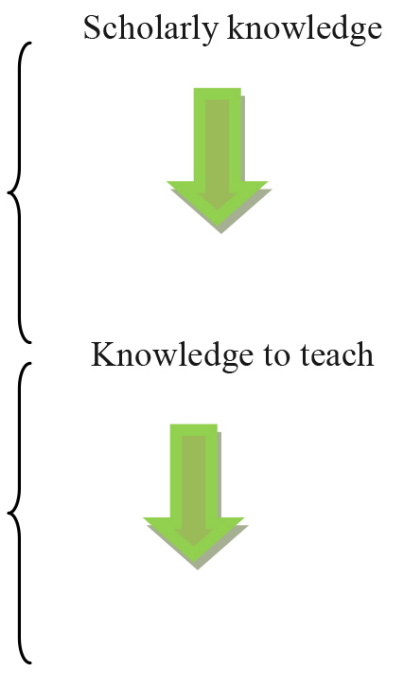

Knowledge taught

Figure 1. The didactic transposition and report to knowledge.

epistemology, psychology, sociology, educational sciences. These tools and borrowed knowledge must be used, altered, and federated to answer the questions on academic knowledge. The object of study of transposition is presented by its authors, as being, epistemological order either anthropological order.

The external didactic transposition: It took place outside the educational system, outside the classroom. Of after Amade-Escot (2007), "the analysis of the external didactic transposition reflects epistemological problems: what are taught knowledge?" Come? What links do have with the social practices of reference? The "noosphere" ensures this passage from the learned knowledge to the know to teach, represented by programs or textbooks she (noosphere) consists of all the actors involved at the intersection of the system of education and society (it therefore envisages: political body which prepares formal programs, teachers, academics, authors of textbooks, inspectors, specialists, parents of students) (etc.). This "noosphere" seeks to redress the balance, consistency between school and society with a double constraint: taught knowledge must be close enough to the learned knowledge (to be recognized and legitimate) and farenough from the knowledge of parents (trivialized by and society). The school must keep its function so that it is recognized as invaluable educational institution. However it appears that the point of departure of the didactic transposition is defined (the learned knowledge). The logic of transposition is said to be "top-down". The question of the didactic transposition is in fact the question of the passing mechanism of learned knowledge to taught knowledge. In this case, it is not to discuss what lies at the source of the didactic transposition, but rather to consider the process of transposition according to a "descending and unilateral" mechanism, of the company to school. Yet a second phase of the didactic, more internal transposition to the class can be considered to be "bottom-up". This second step of the process of didactic transposition which is carried out by teachers and leaves actors to greater freedoms for intervention on content, is teaching when she called internal didactic transposition. We therefore present this step consisting of for example planning environment and the instructions in the situations.

The internal didactic transposition: About the role of the teacher in the didactic transposition, Petitjean (1998) specifies that: "in the class, based on his training and its modes of investment in his work (pedagogy of the project for example), it is far from being a helpless officer, forced by external didactic transposition, but the supervisor [...] didactic transposition dependent discursive event (by reasoning) that constitutes a teaching session. The opportunities and freedoms of actions of actors involved in the class assume that all disciplines are also places of creation, produced by the action of teachers and their interactions with students, "the contents of education emerge in the context of the fact of the joint action of the Professor and the students about the objects of knowledge to the study" (Amade-Escot, 2007). Even if for Chevallard the didactic transposition is complete when the class starts, may yet be that which is played in the classroom (interactions between students and teachers) participated in the creation of the school objects. The temporal distinction between didactic (prior to the 
class) and pedagogy (at the time of the class) is then called into question in this design: the internal didactic transposition must be understood as transformation or effective interpreting programs in educational content, to the passage of knowledge to teach that knowledge which is actually taught. Therefore, this work does not fit in prescriptive logic because in the end it is the teacher who decides what it wants to achieve or not. Indeed the contents of education emerge from the interaction between the teacher, the students and the object whether to study, the logic is rather backward. It also seems that "in its dimension of decision support, educational research contributes to reason possible while leaving to policymakers and stakeholders responsibility for choices they operate" (Amade-Escot, 1998). However, it seems important to seek to identify the parameters to give the interactions between the teacher, the student and the object whether to study the best expectations of success, this "organizing the conditions for the emergence for the student of experiences considered compatible with certain cultural practices" so that students can culturally meaningful experiences within a form of school practice Dénervaud (2010) Understanding of the functioning of the didactic transposition allows to investigate the nature of knowledge (i.e. scholarly and practical social reference) that are not frozen and are sources of debates and conflicts.

The nature of knowledge: Scholarly knowledge: By "scholars knowledge" means "a corpus which is enriched constantly new knowledge recognized as relevant and valid by the specialized scientific community", learned knowledge is essentially the product of researchers acknowledged by their peers, by the University. It is they who evaluate it. Scholarly knowledge is "knowledge validated, produced in a certain place and certain conditions, a world of more or less clear boundaries, "the scientific community", that legitimizes such knowledge, gives them a label of accuracy of interest...” (Audigier, 1988: p. 14).

Knowledge to taught: Knowledge to teach are those "that are described, specified in all of the texts' official" (programmes, instructions officielles, commentaires...); These texts define content, standards, methods” (Audigier, ibid) They are the result of a process of meeting between scholarly knowledge and social practices of references. But it should be not to see in this process of meeting a backward logic in the sense where scholars knowledge would touch. Have produced texts to define, to describe the knowledge that must be taught at each class level (programs). They are produced by an institution whose role is to make this transposition: external transposition. Cutting into major areas, sectors and themes, also sequentialisation of knowledge by year or by cycle. Taught knowledge: The "taught knowledge" are those that the teacher has built and that it will implement in the class. It is that which is set out during school hours. It is from the programs, teachers organize their teaching sequences and is a new breakdown of knowledge into chapters and then in meeting themes, and objectives. They depend on the teacher and his conceptions of learning knowledge.

The curriculum in physical education and sports: In the field of education, it is necessary to establish a programme to achieve the desired objective. In the field of physical education, the child occupies a central position, this is why that programming must be prepared carefully. It should include an alternation between continuity and variety according to the level of education. A curriculum in physical education and sports:

-Must be a structured plan.

-That the planning of the programme is in relation to the needs and expectations.

-That all of the planning of the programme be in relation to the guidelines and philosophy of the organization offering the program.

Schedule a teaching activity, is to develop a combination between the desired objectives and the means available to accomplish its task. This programme must take account of the possibilities of assimilation and expression of the child, at every age.

The teacher to student's needs: Adolescence object of our population of research is the period of determinations and guidelines to meet the requirements and conditions of realization of the students. The diversity of its activities, as the choice made will require a personal organisation of work. The construction of personality through necessary gratuities. Its assertion and social integration needs must find answers to the high school. At this stage of schooling, children have overall features, whose teacher account at sport and physical practices. The first and the second year of secondary education are sensitive classes. The turbulence of adolescence, that know all students, boys and girls, are both new possibilities and unforeseen difficulties. Representations offsets can widen social memberships and differences in sex and age. In physical education and sports, these representations due to adolescence are amplified by the importance of morphological transformations (size, weight, appearance) and their manifestation at different times depending on the students. If this evolution is favourable to the development of the physical benefits in many activities, she sometimes called, in other activities or for some 
adolescents, significant adjustment efforts. It can lead to enthusiasm and commitments, sometimes excessive, but also a strong motivation for physical and sports activities. These differences in the development of the person, characteristic of this period, must not become sources of inequality. That is why the teacher, at this stage of education, striving to follow the evolution of the students and ensure to the keeps their personal commitment and the pleasure they experience as well as the affirmation of their skills. This confirmation through the acquisition of new tangible techniques: they constitute, for the teenager, concrete points of support promoting the restructuring and the identification of personality. The desire for success and self-knowledge is to support: the student is involved in procedures for the understanding of his actions, including those relating to knowledge of the results and their evaluation. Teacher highlights successes and ensures to make acceptable the failures, as a necessary experience on the path of progress. Diversity should be encouraged, but it cannot be carried out in ignorance of the differences. From the perspective of a common culture, should be taken into account in the choice and the implementation of the proposed activities. The teacher may organize the working class by subgroups; Depending on the needs, it alternates the criteria level and affinity, ensuring that no pupil is excluded.

The role of the Professor with respect to different physical activities: In a same school with the same goals, the same class, the same activity, two teachers will build and lead two different lessons. There is a standard of the teacher, a composite sketch of the ideal teacher. The teacher will include careful to pass in his teaching a number of priority objectives:

-Each session of physical education should therefore give rise to a generalized whole body work and aim to improve the respiratory, circulatory, device to cause in particular a satisfactory cardiac fitness.

-L' basic driving education is also subject of care of the teaching staff. It is based on 3 factors:

1. perceptual factors of driving.

2. execution factors.

3. General motor coordination.

Environmental control: educator who uses these types of activities is intended to acquire the student to the taste of the effort, the ability to surpass themselves, the ambition to impose itself in the context of its active life.

Body control: this object is to give awareness to young people of their own bodies, to inform them on psychomotor skills and to remedy their shortcomings morphological and functional. Thus, the concern must be double: develop the powers of the child, the young man or girl, and encourage him to express himself better.

Improvement of psychological qualities and relationships with others: A type of APS with a particular wealth to education. It helps to develop, by disciplining them the qualities of character that occur especially in relationships with others. This ranking of APS, according to their essential effect, enables to establish an annual programme, taking into account the specific needs of students, and a harmonious action research and full. The course of physical education and sports and participation in the athletic association are two opportunities to contribute to education for citizenship: they allow students to be players of their practices, to take decisions and responsibilities, and to occupy different roles. Physical and sports education allows the student to acquire the taste of physical practice, the meaning of the effort and the pleasure to act. At the end of the college, students have in common a set of knowledge and skills that underpin physical, athletic and artistic culture. This allows them to clearly engage in activities of their choice and adopt a citizen valuing solidarity; this still allows them access to knowledge related to the Organization and to maintains it their physical lives so that they are maintained in good health. It can be shown that physical and sports education presents a tool in the fight against failure at school. And then on the motivational level, and from the fact that perception and motivation condition each other, we can think with reason if students opt for: Stadium, ball, Saltire and match rather than for: Court, rope, espalier and relaxation, such an attitude reflects that favourable vision they have of physical and sports education is due in large part, to sporting motivations. The majority of teenagers consider the physical and sports education from a perspective of sports and an orientation more hygiene, more body, appear when their age rises. The motivations "taste for competition" and "life of team" are also shared between the different ages of adolescence. The primary motivation is located rather during the pre-teens, the second adolescence. Therefore, recognize the existence of an ardent antagonism: sport is a highly structured and influential informal social component and has a weekly educational practice. Hours of EPS are often welcomed because they allow a refresh of the body, an oversight of the worries of the spirit and become a moment of relaxation, game, a dedicated stop of mental hygiene and the performance more or less voluntary way.

Representations: The concept of representation, has been reintroduced in the field of active investigation by Moscovici (1961). Since then, he more and more researchers, interested in different domains (social psychology, 
cognitive psychology, education, etc.). It is indeed a fundamental, interdisciplinary, concept that allows "to study behaviours and social relations without distort or make easier them." Moscovici (2003). For Mannoni (1998) social representations are the basis of our psychic life. Chia (1999) adds: "the representation built by a person (or a group) is his link, its the most intimate relationship with the Organization and the environment in which is situated". The concept of social representation is more recent. It is based on the work of S. Moscovici, who is interested in the representations as interactions between individuals and/or groups. This means more representations studied in their dynamics, their development, their evolutions in their content. These social representations include collective and individual aspects. Chia (1999) considers that "representations by the interaction by others, by contact with reality in action. Elsewhere he says: "social representations would be both produced and interindividual, intergroup and ideological process that come into resonance with each other to form institution-specific dynamics and these dynamics are not indifferent as to the construction of the individual representations". If the Genesis, the role, the limits of the representations are very discussed by all researchers in the humanities, the meaning of the concept is common. Can define content, aspects and functions. Similarly, in education sciences, "taking into account of representations by educators is a capital transfer of educational designs." We will not detail any consequences, but take a few very talking examples: taking account of the representations of the student changes the conceptions of learning. And after Meirieu (1989) "a subject so passes of ignorance to knowledge, it goes one representation to another, more efficient." Chappaz (1993) adds "that a subject may therefore take ownership of new concepts by constructing new representations organized in a consistent and functional". They thus confirm the thought of Bachelard (1971) "known against a previous knowledge, by destroying evil made knowledge, overcoming what in mind Similarly, impedes the spiritualization. For Chia (1999), representations of the subject (representations of the environment, knowledge, of course), were built by and in action and contribute to the development of cognitive and affective forms. The action must be present to facilitate a learning situation. In the same manner taking account of the representations of teachers, representations of the "school system", parents and all other individual or collective actors can advance situations otherwise blocked by mutual blindness. This pendant, representations in physical and sports education as student engagement by their driving conduct in various physical activities. The driving conduct a meaningful organization of motor behaviour which has a double perspective: external observation (the observable behavior), and inner meaning (perception, driving anticipation, mental image, etc.). Acting student has a story, an experience, and receives educational, family or even social influences large that darken its representations (Parlebas, 1981). In physical education, almost all of the activities are school practices that are rooted in a social history. Thus, children may or may not recognize and integrate in some sports practices following their social representations. Social integration will be done by the use of the techniques of the body a true collective integration (sports games and sports) for the formation of the character of the education of the social meaning and the acquisition of driving habits promoting the practice of physical activity in general and especially in the context of individual and collective leisure sport. Thus, looking for a better technical performance that is sought by any educational situation proposed in the context of physical education sessions, perfection and efficiency. However, here are some goals that seeks physical and sports education:

-The development of the physical condition of the learner to get used to resist fatigue.

$-\mathrm{L}$ ' improvement and strengthening of the technical and physical capabilities of the learner and its preparation for the realization of honourable results in individual and collective sports.

-The mastery of sports techniques.

-The development and strengthening of tactical intelligence of the learner.

-Knowledge of sports regulations and their effective implementation.

-Better use of technical and physical capacity for achieving good performance.

\section{Materials and Methods}

The objective of our research is to know the current representation of physical education and sport in Tunisia through the content of training offer to the secondary students and try to highlight the usefulness of the integration of new discipline sport. We have organized our research in two major parts:

-The first part for the representation of physical and sports education through the content of training offered to high school students.

-In the second part, we trying to present our hypothesis, which is to highlight the integration of new sport util- 
ity in the educational content of physical education and sports in Tunisia such as the case of Futsal.

To develop a methodological exploration of operative, a technological approach to educational trend is highlighted. Indeed, a viewing session activity Futsal and explanation of the settlement and its specificity is present by a physical education teacher and specialist sports in Futsal and national instructor of this discipline. This phase provides a theoretical cognitive production and practice to end the project to be consistent and applicable. The Protocol is applied to a mixed class composed of 24 students aged between 16 - 18 years of the third year technical high school 9avril1938 Sfax in Tunisia. These students even though they have no experience of practice of Futsal, but they all practice Football at the school. The development of teaching of 8 meetings of a cycle of Futsal project was following a maintains policy semi with experts and specialists in this discipline (coaches and instructors) and a second relationship with composed of ten teachers of physical education and sports teaching team experienced for their opinion of integration of this project in the active phase of practice in establishing highlighting the nature of the Group of students applied to this project the middle of the experience and the material available for this sport. The teacher asked to apply this cycle project is a physical education teacher and sports specialist in Futsal, with an experienced professional over 15 years, this program was proposed by the researcher and negotiated by the teaching team prior to its application. The study protocol is highlighted for the practice of a cycle of 8 meeting aimed at specific that a team consisting of 5 players including a goalkeeper is able to communicate positively with good management of space and individual and collective for decoded techniques an opposing defensive organization and shoot to end to score a goal in accordance with the rules of Futsal. This goal of organizational pace tactically and requesting the technical achievements of agenda socio engine is relatively associate with the specificity of the discipline Futsal and dépondant regulations (see Table A1):

1) The 4 second rule.

2) The rule of 5 metres.

3) The specificities of the goalkeeper.

Following the preparation of the first meeting, the class is divided into three groups consisting each of 8eleves and these groups will be stable throughout the cycle. The distribution of 3 groups comes from an assessment at a meeting No. 1 involving acquisitions, skills driving and technical students enabling the allocation of homogeneous groups to ensure a reliable interaction and cognitive acquisition and effective learning, the structure of the meeting is identical during the cycle and represents the following steps record general warm-up, a warm-up learning situations and specific dépondant the operational objective of each meeting leading to a situation of reference, this situation to detect failures technical, tactical, relational and affective for learner, the duration of each session is 50 minutes are retained for 15 minutes to the reference situation (status of actual game of a futsal match) making calls to its specificity (the cumulative mistakes, and a penalty from 10 metres is granted following the accumulated over five fault committed by a team). At the end of each session the teacher performs an assessment to synthesize and shift its focus to teaching, the teacher's role is essential in the implementation of the project and reveals the development of learning situations, the animation of the meetings and the orientation of the students learning. Practice sessions are recorded by video. The principle of this research is based on analysis of the game sequences, thus the situation of references are cut to shot of game, considered the time of possession of the ball before a break in the game. Indeed according to the duration of the game shot the team shows its ability to manage the game. This method guides to select and analyse effective game sequences leading to decode a defensive organization to shoot at the goal. Observation based analysis guide to determine the number of past, of dribbling and shooting game bump, also interception, cumulative errors, 6, and 10 metre penalty i.e. the modality and the choice of the game adopt.

Materials: Reading of correspondence was through CD. The observation of the matches was carried out TV analysis, calculation and processing operations are performed via a portable microcomputer. The conduct of a game is not reduced to a catalogue of motor actions. It is also and above all a continuous sequence of motor behavior, a possibility of passing from one to the other; it is a system of secondary roles. Thus, we can establish the network of the movement of the roles secondary socio engines. This universal shows these combinatorial secondary roles; it represents the dynamics of multiple paths praxic organization offered to players, since it imposes specific logic of the game. Any player of Futsal will necessarily move within this network and borrow its own line in the common system. It is a fundamental invariant "revealing a limited number of secondary roles and all sports games and lends itself to their networking in the form of the universal” (Parlebas, 1998). "The matrix of the intelligibility of the game, is the matrix of the secondary roles socio-engines. 


\section{Results}

Analysis of the recorded game sequences allow a quantitative analysis intersecting with a qualitative contribution of methodological analysis of discipline. Figure 2 shows the number of shot game recorded observation of video recording of Futsal sessions recorded for the teaching of students, subject of this study. Indeed the number of shot of game varies based on possession of the ball for each team and dependent on the order of positive communications (number of past) interaction with the good management of space and the mobility of players. Also the more kick game is high, more the number of past and the duration of the shot of game are minimal.

The average time from game time is 7 second, variation in the number of shot of game for the second meeting as revealed in Figure 2. The duration and the number of past are relatively constant over the cycle and presents an increase in session 3, the objective of this session is to invest the playing against a defense organized space and keep the ball for accessing the purpose, this finding collaborates with Gréhaigne, billiards and Laroche (1999) "the more game sequence is long." more the team proves that she is able to manage different settings of the game, and in particular the opposing game, combining various tactical units. Offensive and defensive efficiency: Figure 3 shows an average evolution of the number of shooters and the number irregularity of purpose according to the cycle of Futsal sessions.

The results shows that the shot count is very low during the second and third meeting of the cycle of Futsal, this number clearly increases during other sessions and the number of aim to stabilise positively marking a remarkable increase. Offensive efficiency follows a progression valuing by goals mark, although sessions 2 and 3 are orienting to a collective defensive organization, defensive efficiency and well-organized in defense space are two factors accessing this results. Any time the average number of shot on goal presents a growing evolution during the marking cycle a rebalance force reports and collective organizations of the teams in attack and defence. Impact of the rules of the game on the production of collective action: The cumulative mistakes are mistakes committed by a few players and recorded for his teams for each game period, these faults are fouls punishable by a direct free kick, any time the number of errors increases during the game, a 10 metre penalty is awarded against the team that more than 5 fautes by team and for each period of play.

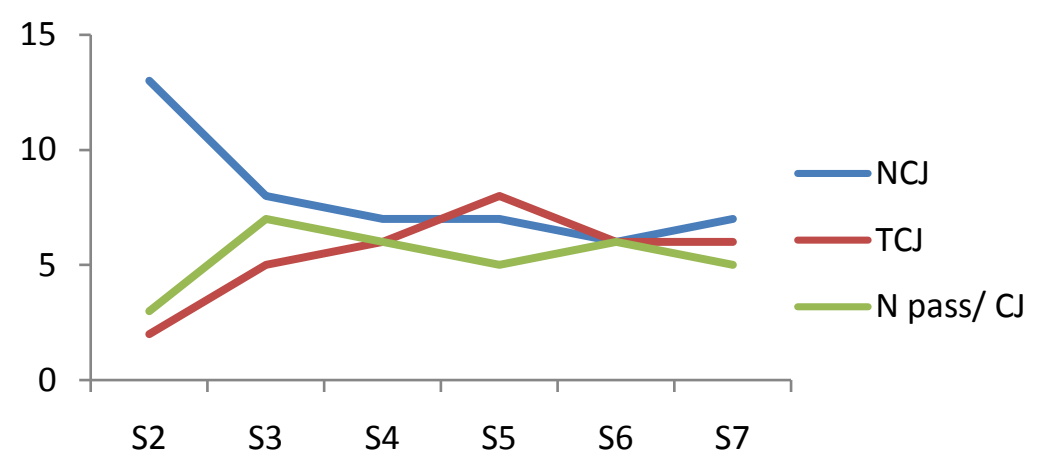

Figure 2. Result of variation of the NCJ, TCJ and NP (NCJ numbers of game shot, TCJ time to kick game, Npass/CJ number of past game bump) cycle of Futsal Court.

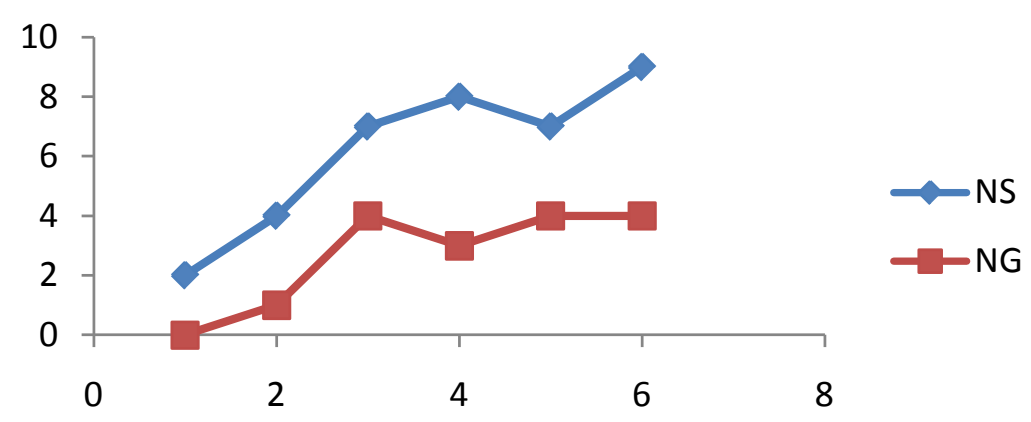

Figure 3. Result of variation of the NS and NG (NS number of shots, NG numbers of goals) cycle of Futsal Court. 


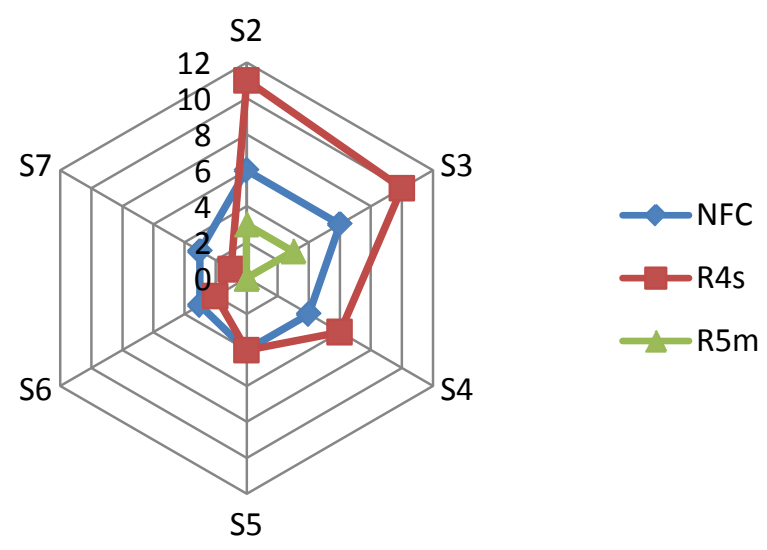

Figure 4. Result of variation of the NFC (number of cumulative errors), R4s (rule of 4 seconds) R5m (rule of 5 metres) cycle of Futsal Court.

The average change in the number of accumulated team fouls is a determining adaptation of individual and collective skills with the specificity of the discipline and the identifier of its rules. This adaptation is illustrated in Figure 4 descending space of this determinant is marked clearly on the basis of practical Futsal sessions. Any time the number of cumulative errors decreased from the fourth meeting, valuing input adequate and effective game. This positive development of students in the acquisition of the contents of the rules of Futsal is mark by respect for progressive rule of the 4 second as time allowed the resumption of game and the ratio of the 5 meter distance which an opponent must move away from the ball to ensure the regulatory recovery of the game.

\section{Discussions}

Futsal model in physical education and sports as the form of school practice requiring adaptation to the rules of the game ensures a collective valuation with a cognitive report stimulating action of the professor for a dynamics of target group sets (Parlebas, 1998). Collective recovery in social roles and the construction of individual and collective motors knowledge are the traits of contribution of this research and the discipline of Futsal for the student and the teacher who attend the practice of this discipline, even a co-construction of knowledge can produce meaningful collective actions, methodological and social learning in a team sport (Amade-Escot, 2007). In this regard, the establishment of the rule of cumulative mistakes brand driving acquisitions collective and individual in the game. This pendant from specificities of the Futsal regulation directs the student to master its displacement and its commitment during the game leading to a reflection of management knowledge and technical, tactical and physical skill. Collective efficiency offensive and defensive allowing an adequate adaptation and a mastery of the concept of decoding of a defensive didactic organization is organized by management of knowledge and experience for developing cognitive and socio-moteur student. Integration of a sport culture in the programming of physical and sports education in Tunisia requires the determination and identification of its components, as well as his contribution on the learner. Programming of a cycle of Futsal in the teaching of physical education and sports in Tunisia has been a development of a motivational culture providing an important contribution to the practitioners - teacher and pupil. It is an essential kernel of progression from cultural image and of civilization (Moscovici, 1989). It is a way of progress in physical education and motivates sportive learner to discover new content and apply it in real and practical and stimulating situation knowing the teacher to make a methodological approach valuing his teaching and promoting its didactic action of conversion of content to teach its learners to ease through his speech whether ownership of learner (Perrenoud, 1998). This ideological representation of knowledge leads to dependent structural analysis of the instructional design of the unstable content and dépondant of various components of the teaching learning process. This study will have the perspective to apply to different levels of school education by ensuring an applicable and reliable program and eliminating the reproduction of the same educational content for students during the entire period of his schooling after a design change at the level of methodological and educational organizations in the programming of sport and physical education in Tunisia. 


\section{References}

Amade-Escot, C., Refuggi, R., \& Amans-Passaga, C. (2007). Practical Teachers and Specificities of the Didactic Action in Rural Areas: Intervention in School Sports Association. Crossroads of Education 2/2007 (No. 24), 131-147. www.cairn.info/revue-carrefours-de-l-education-2007-2-page-131.htm.

Amade-Escot, C. (1998). Contribution of Educational Research to the Analysis of Education: A Case Study. The Teaching Contract.

Audigier (1988). Teaching History, Geography and Social Sciences: Introductory Remarks.

Bachelard, G. (1971). The Training of the Scientific Mind. Vrin, Paris. http://www.meirieu.com/COURS/texte11.pdf

Chappaz, G. (1993). Representations of the World as Educational Springboard. Sciences Humaines, No. 27.

Chevallard, Y. (1985). The Didactic Transposition-Of Learned Knowledge to Knowledge Taught. La pensée wild, Grenoble (126 p.). Second Enlarged Edition 1991.

Chia, J. (1999). A “Rhizomic” Model of Organizational. Change and Transformation: Perspective from a Metaphysics of Change. British Journal of Management, 10, 209-227. http://dx.doi.org/10.1111/1467-8551.00128

Mannoni, P. (1998). Social Representations. Paris, PUF. http://197.14.51.10:81/pmb/Que\%20sais\%20je/Sociologie/les\%20representations\%20sociales\%20-\%20Mannoni\%20Pierr e.pdf

Meirieu, P. (1989). Differentiated Instruction: Confinement or Opening?

Mercier, A. (2002). The Didactic Transposition, a Theory of Teaching Space. Briefing Note. Towards a Didactic Compared. Revue Française de Pédagogie, 141, 135-171.

http://ife.ens-lyon.fr/publications/edition-electronique/revue-francaise-de-pedagogie/INRP_RF141_13.pdf http://dx.doi.org/10.3406/rfp.2002.2922

Moscovici, S. (2003). Collective Representations to Social Representations: Elements for a Story. In: Jodelet, D., Ed., Social Representations (pp. 62-86). Presses Universitaires de France. https://www.Cairn.info/Les-representations-sociales--9782130537656-page-79.htm

Moscovici, S. (1961). Psychoanalysis His Image His Public. Paris: PUF. https://www.PUF.com/content/La_psychanalyse_son_image_et_son_public

Parlebas, P. (1981). Contribution to a Lexicon Commented in Science of Driving Action. Paris: National Institute of Sport and Physical Education.

Perrenoud, P. (1998). The Didactic Transposition from Practices: Knowledge Skills. Journal of Sciences of Education (Montreal), 24, 487-514. http://www.unige.ch/fapse/SSE/teachers/perrenoud/php_main/php_1998/1998_26.html\#copyright

Petitjean, A. (1998). The Didactic Transposition in French. Practice No. 97-98. http://www.Pratiques-cresef.com/resum097.PDF 


\section{Annexes}

\section{Table A1. Observation grid.}

\begin{tabular}{|c|c|c|c|c|c|c|c|c|c|c|c|c|c|}
\hline & $\begin{array}{l}\text { Number } \\
\text { of blow } \\
\text { of the } \\
\text { game }\end{array}$ & $\begin{array}{c}\text { Length } \\
\text { shot of } \\
\text { the } \\
\text { game }\end{array}$ & Dribble & Pass & Interception & Unmarking & $\begin{array}{l}\text { Shooting } \\
\text { framed }\end{array}$ & $\begin{array}{c}\text { Shooting } \\
\text { non } \\
\text { framed }\end{array}$ & $\begin{array}{c}\text { Penalty } \\
10 \mathrm{~m}\end{array}$ & $\begin{array}{l}\text { Penalty } \\
6 \mathrm{~m}\end{array}$ & $\begin{array}{l}\text { Cumulative } \\
\text { fault }\end{array}$ & $\begin{array}{l}\text { Shot } \\
\text { on } \\
\text { goal }\end{array}$ & 4S \\
\hline 1 & & & & & & & & & & & & & \\
\hline 2 & & & & & & & & & & & & & \\
\hline 3 & & & & & & & & & & & & & \\
\hline 4 & & & & & & & & & & & & & \\
\hline 5 & & & & & & & & & & & & & \\
\hline 6 & & & & & & & & & & & & & \\
\hline 7 & & & & & & & & & & & & & \\
\hline 8 & & & & & & & & & & & & & \\
\hline 9 & & & & & & & & & & & & & \\
\hline 10 & & & & & & & & & & & & & \\
\hline 11 & & & & & & & & & & & & & \\
\hline 12 & & & & & & & & & & & & & \\
\hline 13 & & & & & & & & & & & & & \\
\hline 14 & & & & & & & & & & & & & \\
\hline 15 & & & & & & & & & & & & & \\
\hline 16 & & & & & & & & & & & & & \\
\hline 17 & & & & & & & & & & & & & \\
\hline 18 & & & & & & & & & & & & & \\
\hline 19 & & & & & & & & & & & & & \\
\hline 20 & & & & & & & & & & & & & \\
\hline
\end{tabular}

\section{Submit or recommend next manuscript to SCIRP and we will provide best service for you:}

Accepting pre-submission inquiries through Email, Facebook, LinkedIn, Twitter, etc.

A wide selection of journals (inclusive of 9 subjects, more than 200 journals)

Providing 24-hour high-quality service

User-friendly online submission system

Fair and swift peer-review system

Efficient typesetting and proofreading procedure

Display of the result of downloads and visits, as well as the number of cited articles

Maximum dissemination of your research work

Submit your manuscript at: http://papersubmission.scirp.org/ 